\title{
Differenz
}

Revista internacional de estudios heideggerianos y sus derivas contemporáneas

AÑO 1 NÚMERO 0: JULIO DE 2014. e-ISSN: 2386-4877 - DOI: 10.12795/Differenz.2014.i00.14

[pp. 141-163]

\section{Heidegger y los Cuadernos Negros. El resurgimiento de la controversia nacionalsocialista}

\author{
Jesús Adrián Escudero \\ Universidad Autónoma de Barcelona
}

${ }^{1}$ El silencio de Heidegger tras el descubrimiento de los horrores del nazismo fue notorio. En la actualidad, todavía se intentan encontrar las razones últimas que le llevaron a simpatizar con el movimiento nacionalsocialista. Sin embargo, Heidegger no permaneció en silencio. Un número importante de documentos -algunos de ellos de reciente publicación- plasman con claridad su opinión personal y política. En ellos admite que apoyó al partido nazi, que se equivocó y cometió errores y que no supo ver lo que iba a suceder después de dejar el cargo de Rector de la Universidad de Friburgo en el año 1934. Pero también se apresura a añadir excusas y minimizar el grado de su envolvimiento. Afortunadamente, la reciente edición de su diario filosófico en la primavera de 2014 conocido en el marco de los estudios heideggerianos como Cuadernos negros (Schwarze Hefte)- permiten ahora arrojar nueva luz sobre su nivel de compromiso personal con el nacionalsocialismo y reevaluar la dimensión política de su pensamiento. ${ }^{2}$

1 El presente trabajo se ha realizado en el marco del Senior Fellowship otorgado por la Fundación Humboldt y el proyecto de investigación financiado por el Ministerio de Educación, Cultura y Deporte con el número de referencia FFI2013-44418-P.

2 Llegará el momento en que se sabrá cada cosa que Heidegger dijo y escribió, en que se conocerán cada aspecto concreto de su vida y cada detalle de su obra. Llegado ese momento, iटंquizá!?, se logrará establecer una nueva relación con su herencia filosófica, liberada del escrutinio político y la búsqueda constante de huellas nacionalsocialistas en su pensamiento (cf. BEISTEGUI, M. (1998). Heidegger and Politics Dystopias. London and New York: Routledge, pp. 3-4). 
Sin duda, la publicacion de los tres primeros volúmenes de los llamados Cuadernos negros ha encendido nuevamente la polémica. La controversia arrancó incluso antes de la publicación de esos cuadernos. La circulación de algunos extractos del libro generó una ácida discusión en diferentes revistas alemanas, francesas e italianas entre defensores y detractores del pensamiento y de la figura de Heidegger. ${ }^{3}$ Es incuestionable que los Cuadernos negros contienen algunas afirmaciones polémicas y ambivalentes en torno al tema de los judíos y el judaísmo. Un hecho que ha vuelto a despertar la espinosa cuestión del anti-semitismo y provocado una reapertura del llamado Caso Heidegger.

Con todo, ante la abundancia de materiales y evidencias documentales de las que se dispone en la actualidad hay que ser prudentes y cautelosos a la hora de replantear el problema de Heidegger, la política y el antisemitismo. Más que preguntar “¿Fue Heidegger un nazi?”, “¿Fue Heidegger un antisemita?”, nos parece más adecuado interrogarse por el tipo de nacionalsocialismo que él aspiró a establecer durante su período como rector de la Universidad de Friburgo. Además, sus discursos políticos de los años treinta no se pueden leer al margen del contexto socio-histórico alemán, caracterizado por la caída de la República de Weimar y el ascenso al poder del partido nacionalsocialista. Para Heidegger, la identidad alemana se fundamenta en el arraigo en la propia tierra natal. A partir de esta idea de fondo, el presente trabajo aborda las siguientes cuatro cuestiones.

En primer lugar, se explica qué son los Cuadernos negros. En segundo lugar, se ofrece una breve descripción del llamado Caso Heidegger y una revisión del estado actual de la investigacion en torno a la vinculacion heideggeriana con el nacionalsocialismo. En tercer lugar, se analizan la función y el significado espiritual que Heidegger otorga al arraigo (Bodenstandigkeit), a la tierra natal (Heimat) y al pueblo (Volk) como elementos vertebradores de la identidad alemana. Este análisis se realiza desde la influencia que

3 A este respecto cabe mencionar las palabras de Eric Aeschimann en Le Nouvel Observateur comentando la polémica entre François Fédier, Hadrien France-Lanorad y Peter Trawny (7 de diciembre de 2013). También merece la pena destacar las opiniones de Donatella di Cesare, Vicepresidenta de la Heidegger Gesellschaft y miembro de la comunidad hebrea de Roma, emitidas en una entrevista publicada en La Reppublica (18 de diciembre de 2013), los comentarios de Jürg Altweg sobre la debacle para la filosofía francesa aparecidos en la Frankfurter Allgermeine Zeitschrift (13 de diciembre de 2013) y las réplicas del editor alemán de los Cuadernos negros, Peter Trawny, publicadas en la revista alemana Die Zeit-Online (27de diciembre de 2013). Para una contrarréplica del co-editor de las Obras completas, Friedrich-Wilhelm von Herrmann, véase el suplemento cultural de la revista italiana Avvenire (17 de julio de 2014). Otros intérpretes alemanes de la obra de Heidegger -como el biográfo Rüdiger Safranski y los profesores Günther Figal y Klaus Held- han escrito y participado en programas radiofónicos y televisivos para discutir el asunto. De igual manera, la prensa internacional ha tomado parte en el debate, recurriendo a frases y citas hace tiempo publicadas, en las que Heidegger expresa abiertamente su postura ante el nacionalsocialismo y el judaísmo. 
ejercen sus lecturas de Yorck, Spengler y otros representantes del movimiento conservador de la derecha alemana contrarios a la República de Weimar. Y, en cuarto lugar, se dirime la espinosa cuestión del antisemitismo en Heidegger.

\section{1.¿Qué son los Cuadernos negros?}

Alrededor del año 1930, momento en el que se inicia el conocido viraje (Kehre), Heidegger emprendió la redacción de textos que intentaban aclarar elementos centrales de su pensamiento más esotérico, en especial los experimentos filosóficos y conceptuales en torno al pensamiento del acontecimiento apropiador (Ereignis-denken) que empieza a aflorar en Contribuciones a la filosofía (1936/38). Su hermano Fritz Heidegger ya aludía a estos cuadernos en una carta a Hugo Friedrich en 1950: "Heidegger es completamente él mismo en los manuscrito propios (no en las lecciones y conferencias); estos propios manuscritos están aquí casi intactos, sólo pocos han sido transcritos. Aquí aparece aquella actitud fundamental que debería ser principio y fin de todo filosofar; yo la llamo desde hace tiempo humildad. Aquí, en estos manuscritos se hallan ocultas las preciosidades y delicias del pensar heideggeriano. Espero que permanezcan ocultas largo tiempo." ${ }^{4}$

El propio Heidegger dispuso en un gesto -por cierto muy nietzscheano- que estos manuscritos debían mantenerse clausurados por lo menos cien años, tal y como se desprende de los testimonios de su hijo Hermann Heidegger: "Cuando yo muera, lo que tú deberás hacer será sellar todo lo que dejo, amarrarlo y clausurarlo durante cien años en un archivo. La época todavía no está lista para entenderme.." ${ }^{5}$ Ya sabemos las reservas que mostraba Heidegger ante la elaboración de unas Obras completas. Todavía en 1972 escribe a su editor Vittorio Klostermann: "Lamenta-blemente no puedo aceptar su deseo de editar una edición integral de mis trabajos» ${ }^{6}$. Sin embargo, el editor logra convencer

\footnotetext{
4 Esta carta se encuentra en el Archivo de la Universidad de Friburgo. Aquí la citamos a partir de xolocotzı, A. (2009). Facetas heideggerianas. México: Los Libros de Homero, p. 66.

5 Entrevista a Hermann Heidegger, citado en Xolocotzi, Facetas heideggerianas, p. 66.

6 Citado en xolocotzl, Facetas heideggerianas, p. 66. Para más detalles sobre la historia de la Gesamtausgabe y de los esfuerzos por conservar los manuscritos ante el temor de perderlos justo al final de la Segunda Guerra Mundial, consultar el citado libro de Xolocotzi (especialmente las páginas 67-70). Heidegger presiente el peligro que corren sus manuscritos por lo menos desde agosto de 1944. Su intranquilidad lo llevará a guardarlos en una gruta a orillas del Danubio cerca de Beuron (véase la carta del 15 de abril de 1945 dirigida a su esposa en HEIDEGGER, M. (2008). iAlma mía! Cartas de Martin Heidegger a su mujer Elfride 1915-1970. Buenos Aires: Manantial, p. 244s). Por lo que sabemos, este plan no se llegó a ejecutar y los manuscritos retornaron a Meßkirch con Fritz Heidegger y, finalmente, fueron depositados en el Literaturarchiv Marbach.
} 
a Hermann Heidegger para formar un frente común. Y, finalmente, en 1973 Heidegger accede a la propuesta de una edición integral.

Los Cuadernos negros, por deseo del propio Heidegger, deberían haberse publicado una vez editos los 102 volúmenes que componen las Obras completas (Gesamtausgabe). Sin embargo, dicho deseo no se cumplió al pie de la letra. Ante el gran interés generado por estos cuadros, tres de los nuevos volúmenes se publicaron en la pasada primavera de 2014 en la editorial alemana Vittorio Klostermann.

Ahora bien, ¿en qué consisten los Cuadernos Negros? Desde hace décadas estos textos constituyen uno de los mitos en torno a la figura de Heidegger, uno de los secretos mejor guardados en el Archivo Heidegger de Marbach. A juicio de los pocos que han tenido acceso a ellos, se trata del concentrado de su filosofía. El coeditor de la Gesamtausgabe y último ayudante de Martin Heidegger, Friedrich-Wilhelm von Herrmann, expresa la importancia de estos Cuadernos negros en los siguientes términos: "Cosa aparte son los volúmenes 94-102 de la cuarta sección. Esos volúmenes contienen los así llamados Cuadernos negros y Cuadernos de trabajo, como los llamaba Heidegger. Empiezan con el año 1931, es decir, justamente al inicio del pensamiento de la historia del ser y terminan el año de su muerte. Esos Cuadernos negros acompañan todo su caminar desde 1931 hasta 1976. En este sentido forman un manuscrito abundante y, temporalmente, contextual, pese a ser apuntes que nuevamente iniciaban, cada semana, cada mes, cada año. (...) Lo que aquí hay es una densificación pensativa. (...) No es solamente una forma estilística diferente, ahí menciona muchas cosas que tal como las escribió no escribiría en ninguno de los otros ensayos, ni siquiera en los grandes. Por eso es que estos nueve volúmenes son de mucha importancia."7

En definitiva, los Cuadernos negros se componen de treinta y cuatro cuadernillos con cubiertas enceradas de color negro, en los que Heidegger redactó una serie de apuntes entre 1931 y 1976 . Los primeros catorce cuadernillos -los que ahora se han publicado - se titutalan Reflexiones (Überlegungen) y abarcan los años transcurridos entre 1931 y $1941 .^{8}$ Los otros veinte están en proceso de edición y se distribuyen de la siguiente manera: nueve corresponden a Observaciones (Anmerkungen), dos a Cuadernos cuádruples (Vier Hefte), otros dos a Vigilias (Vigilae), uno a Nocturno (Notturno), dos a Guiños (Winke) y cuatro

7 xolocotzı, A. (2003). "En torno a Heidegger. Diálogo con Friedrich-Wilhelm von Herrmann". Revista de Filosofía 108, pp. 41ss. También citado en Xolocotzi, Facetas heideggerianas, p.68/n. 1.

8 Cf. HEIDEGGER, M. (2014). Überlegungen II-VI (Schwarze Hefte 1931-1938). Frankfurt am Main: Vittorio Klostermann (GA 94), HEIDEGGER, M. (2014). Überlegungen VII-XI (Schwarze Hefte 1938/39). Frankfurt am Main: Vittorio Klostermann (GA 95) y HEIDEGGER, M. (2014). Überlegungen XII-XV (Schwarze Hefte 1939-1941). Frankfurt am Main: Vittorio Klostermann (GA 96). 
a Provisionales (Vorläufiges). En los últimos años han aparecido otros dos cuadernos, Megistón (Megiston) y Palabras fundamentales (Grundworte). Por el momento no está previsto que estos dos últimos cuadernos se publiquen en el marco de la Gesamtausgabe.

¿A qué se debe toda la expectativa generada alrededor de dichos textos? Hasta hace poco se pensaba que los Cuadernos negros constituían una especie de diario filosófico, un bitácora pensante que nos proporcionaría la clave de lectura de la obra heideggeriana. Sin embargo, Heidegger nos sorprende una vez más. Como el mismo afirma no se trata de aforismos y de ningún tipo de literatura sapiencial, sino de "sencillas avanzadillas que en general intentan conquistar el camino de una reflexión todavía indecible para un preguntar inicial, que a diferencia del pensamiento metafísico se llama onto-histórico."9 Las diferentes representaciones que encontramos en la historia de la metafísica son irrelevantes. Lo que aquí resulta decisivo es cómo se pregunta por el ser, no lo que se dice sobre él. En su escrito Mirada retrospectiva (1936/38), Heidegger se refiere a sus cuadernos, sobre todo a las Reflexiones II, IV y V, recordando que en ellos se conservan "los estados anímicos fundamentales del preguntar y las consignas a los horizontes más extremos de todo intento pensante." ${ }^{10} \mathrm{El}$ hecho de subrayar "los estados anímicos fundamentales del preguntar" refuerzan la idea de que en estas reflexiones se trata de "intentos pensantes". En este sentido, el editor de los cuadernos decide colocar una indicación que probablemente se remonta al inicio de los años setenta, en la que se dice que los Cuadernos negros "no son apuntes para un sistema planificado, sino que en el fondo se trata de intentos de un nombrar sencillo."11 No deja de sorprender que en todos estos casos los Cuadernos negros se consideren simples intentos, aproximaciones a un pensar más inicial, tanteos de un decir lo indecible, tentativas de pensar lo impensado. Si lo que resulta "decisivo" es "cómo se pregunta", esto es, como se trae a palabra el sentido del ser, entonces nos encontramos en los Cuadernos negros con un nuevo estilo de escritura. Junto a sus lecciones, libros, conferencias, tratados y discursos, nos encontramos con un estilo peculiar que se aproxima bastante lo que podríamos denominar un "diario pensante" (Denktagebuch).

En general nos encontramos con reflexiones filosóficas mezcladas con anotaciones sobre sucesos del momento. Así, en las más de mil dos cientas páginas encontramos

9 HEIDEGGER, M. (2014). Überlegungen VII-XI (Schwarze Hefte 1938/39). Frankfurt am Main: Vittorio Klostermann, GA 95, p. 274.

10 HEIDEGGER, M. (1997). „Rückblick auf den Weg“. En Besinnung (1936/38). Franfkurt am Main: Vittorio Klostermann, GA 66, p. 426.

11 HEIDEGGER, M. (2014). Überlegungen II-VI (Schwarze Hefte 1931-1938). Frankfurt am Main: Vittorio Klostermann, GA 94, p. 1. 
indicaciones sobre el rumbo que tomó su filosofía después de Ser y tiempo y precisiones sobre su segunda obra fundamental, Contribuciones a la filosofía. También hallamos opiniones acerca del período del rectorado en Friburgo y múltiples reflexiones sobre los peligrosos signos de la creciente maquinalización de la vida cotidiana y la consumación de la técnica como expresión de la volutnad de poder, cuyo "último acto" se producirá cuando "la tierra misma explote en el aire" y "la humanidad contemporánea desaparezca". ${ }^{12}$ Pero junto a estas interesantes observaciones sobre el itinerario de su pensamiento y su diagnóstico del devenir de la historia de la metafísica, Ilaman la atención algunos juicios contundentes sobre el nacionalsocialismo y, a partir de 1938, sus severos comentaros sobre el judaísmo.

Como bien observa el editor alemán de los cuadernos, Peter Trawny, no hay evidencia de que Heidegger hubiera leído los Protoclos de los sabios de Sión, que difundían la tesis de una conspiración mundial judía. ${ }^{13}$ No obstante, una parte de los discursos de Hitler difundían los estereotipos ahí planteados, que Heidegger asimiló y asoció a su problemàtica filosófica en diversos momentos de su obra. Hablamos aquí de la asociación entre la calculabilidad y el modo de pensar de la época contemporánea y la cosmovisión judía que, de acuerdo con Heidegger, se identifica con el espíritu del cálculo. De este manera, la crítica de la modernidad se une y se extiende a la del judaísmo, Así, en Reflexiones VIII, 5 escribe: "Una de las figuras más ocultas de lo gigantesco y quizá la más antigua sea la de la historicidad del cálculo, el empuje y la mezcla confusa mediante la cual se funda la ausencia de mundo del judaísmo." ${ }^{14} \mathrm{Y}$ en Reflexiones XII, 24 sostiene que: "El actual aumento de poder del judaísmo tiene su fundamento en el hecho de que la metafísica de Occidente, sobre todo en su desarrollo moderno, proporciona el punto de partida que hace visible un racionalidad vacía y una capacidad de cálculo que de

12 HEIDEGGER, M. (2014). Überlegungen XII-XV (Schwarze Hefte 1939-1941). Frankfurt am Main: Vittorio Klostermann, GA 96, p. 238. A juicio de Heidegger, esto no es una desgracia, sino más bien la ocasión para una primera "purificación del ser (Reinung des Seins) de sus más profundas desfiguraciones provocadas por la hegemonía del ente." (HEIDEGGER, ibid, p. 238). Heidegger se distancia claramente de los principios de purificación racial del nacionalsocialismo. Pero, al mismo tiempo, interpreta el judaísmo mundial (Weltjudentum) como la cúspide de la manifestación ontohistórica de la calcubalidad y la maquinación (HEIDEGGER, ibid, p. 46). Hay que tener claro que las manifestaciones de Heideegger no deben interpretarse en términos políticos. Se trata, más bien, de su particular interpretación filosófica de la historia del ser. Dicho en otras palabras, el judaísmo junto con el bolchevismo, el americanismo y el nacionalsocialismo-es un fenómemo onto-histórico. 13 Cf. TRAWNY, P. (2014). Heidegger und der Mythos der jüdischen Weltverschwörung. Frankfurt am Main: Vittorio Klostermann, pp. 23ss.

14 HEIDEgGeR, M. (2014). Überlegungen VII-XI (Schwarze Hefte 1938/39). Frankfurt am Main: Vittorio Klostermann, GA 95, p. 97. 
otro modo pasaría desapercibida." ${ }^{15}$ Afirmaciones de este tipo han vuelto a despertar la cuestión del antisemitismo y reavivado el famoso Caso Heidegger. Estos primeros tres volúmenes recién publicados brindan elementos suficientes para derribar la imagen de un Heidegger apolítico y rural recluído en su cabaña, que desatendía la realidad socio-política de su tiempo.

\section{El Caso Heidegger: nuevas evidencias documentales y estado actual de la investigacion}

La recepción de la obra heideggeriana ha mostrado profundas dudas acerca de la viabilidad política de su pensamiento. Esas dudas se remontan al escándalo político -el llamado Caso Heidegger -que desembocó en la publicación de los trabajos pioneros de Derrida (1987), Farías (1987), Lyotard (1988) y Ott (1989) en torno a la implicación de Heidegger con el nacionalsocialismo. ${ }^{16}$ A estos primeros trabajos sobre la dimensión política de la obra heideggeriana, le siguieron los de Nolte (1992), Pöggeler (1990), Rockmore (1991), Sluga (1993), Young (1997) y Wolin (1993), entre otros. ${ }^{17}$ A la luz de este escándalo se tomó conciencia de que Heidegger ya no puede ser leído de la misma manera y que sus lazos con el nacionalsocialismo eran innegables.

Por otra parte, tenemos la historia oficial contada por el mismo Heidegger en diferentes momentos de su vida: desde su ensayo retrospectivo El rectorado 1933/34: hechos y reflexiones y su carta del 4 de noviembre de 1945 dirigida al Comité de Depuración de la Universidad de Friburgo, hasta su conocida entrevista con la revista Der Spiegel en $1966 .{ }^{18}$ A ello se suman la reciente publicación de discursos políticos, actos académicos

15 HEIDEGGER, M. (2014). Überlegungen XII-XV (Schwarze Hefte 1939-1941). Frankfurt am Main: Vittorio Klostermann, GA 96, p. 46.

16 Cf., respectivamente, DERRIDA. J. (1987). De l'esprit: Heidegger et la question. Paris: Editions Galilée; FARIAS, V. (1987). Heidegger et le nazisme. Paris: Éditions Verdier; LYTORAD, F. (1988). Heidegger et "les juifs". Paris: Débats; OTT, H. (1989). Martin Heidegger. Unterwegs zu seiner Biographie. Frankfurt am Main: Campus Verlag.

17 Cf., respectivamente, NOLTE, E. (1992). Heidegger. Politik und Geschichte im Leben und Denken. Berlin: Propyläen; PÖGGELER, O. (1990). Der Denkweg Marin Heideggers (3rd edition). Pfullingen: Neske; RockMORE, T. (1991). On Heidegger's Nazism and Philosophy. Berkeley and Los Angeles: University of California Press; SLUGA, H. (1993). Heidegger's Crisis: Philosophy and Politics in Nazi Germany. Cambridge, MA: Harvard University Press; wolın, R. (1993). The Heidegger Controversy. A Critical Reader. Cambridge, CA: MIT Press; young, J. (1997). Heidegger, Philosophy, Nazism. Cambridge: Cambridge University Press.

18 Cf., respectivamente, HEIDEGGER, M. (2000). „Das Rektorat 1933/34 - Tatsachen und Gedenken (1945)". In Reden und andere Zeugnisse (GA 16). Frankfurt am Main: Vittorio Klostermann, pp. 372-394; HEIDEGGER, M. (2000). „Antrag auf die Wiedereinstellung in die Lehrtätigkeit Reintegrierung (November 4, 1945)“. In Reden und andere Zeugnisse (GA 16). Frankfurt am Main: Vittorio Klostermann, pp. 397-404; HEIDEGGER, M. (2000). „Spiegel-Gespräch mit Martin Heidegger 
y entrevistas radiofónicas de los años treinta en el volumen 16 de las Obras completas, el conocido Discurso del Rectorado, el controvertido texto de 1933/34 sobre el Estado, la historia y la naturaleza, las reflexiones entre 1936 y 1938 y los comentarios desperdigados sobre el pueblo judío que encontramos en Contribuciones a la filosofía. ${ }^{19}$ Asimismo, se dispone de las autorizadas opiniones expresadas por contemporáneos de Heidegger, como las de Karl Löwith (1986), Hermann Mörchen (1981), Hans Jonas (2003), Karl Jaspers (1978) y Heinrich Petzet (1977). ${ }^{20}$

Después de unos años de silencio, el Caso Heidegger se reavivó con los libros de Farías (2009) y Feye (2005), ${ }^{21}$ que desvelaron nuevos documentos y escritos políticos que pretenden demostrabar el nazismo de Heidegger. También se editó el volumen coordinado por Tauereck (2008), que establece una comunidad de intereses entre Heidegger y el nacionalismo. ${ }^{22}$ Sin embargo, este tipo de interpretación extremadamente politizada muestra algunos errores documentales y un elevado grado de unilateralidad, ${ }^{23}$ como han puesto de manifiesto las últimas investigaciones de Denker y Zaborowski (2009), Grosser (2011), Xolocotzi (2013) y Zaborowski (2010). ${ }^{24}$

(September 26, 1966)“. In Reden und andere Zeugnisse (GA 16). Frankfurt am Main: Vittorio Klostermann, pp. 652-683.

19 Cf., respectivamente, HEIDEGGER, M. (2000). Reden und andere Zeugnisse. Frankfurt am Main: Vittorio Klostermann; HEIDEGGER, M. (2000). „Die Selbstbehauptung der deutschen Universität (Mai 27, 1933)“. In Reden und andere Zeugnisse. Frankfurt am Main: Vittorio Klostermann, pp. 107-117; HEIDEGGER, M. (2009). „Über Wesen und Begriffe von Natur, Geschichte und Staat. Übung aus dem Wintersemester 1933/34". In DENKER, A. \& ZABOROWSKI, H. (ed.). Heidegger und der Nationalsozialismus. Heidegger Jahrbuch 4 - Dokumente (53-88). München: Karl Alber, pp. 53-88; HEIDEGGER, M. (1997). Besinnung. Frankfurt am Main: Vittorio Klostermann (GA 66).

20 Cf., respectivamente, LöWITH. K. (1986). Mein Leben in Deutschland vor und nach 1933. Stuttgart: Metzler; MÖRCHEN, H. (1981). Adorno und Heidegger.Untersuchung einer philosophischen Kommunikationsverweigerung. Stuttgart: Klett-Cotta; JONAS, H. (2003). Erinnerungen. Frankfurt am Main: Suhrkamp; JASPERS, K. (1978). Philosophische Autobiographie. München: Piper; PETZET, H. (1977): Erinnerungen an Martin Heidegger. Pfullingen: Neske.

21 Cf. FARíAs, V. (2009). Heidegger y el nazismo (edición ampliada). Palma de Mallorca: Objeto Perdido ; FAYE, E. (2005). Heidegger et l'introduction du nationalsocialisme dans la philosophie. Paris: Albin Michel.

22 TAUReCK, B. (ed.) (2008). Politische Unschuld? In Sachen Martin Heidegger. München: Wilhelm Fink.

23 El caso más flagrante es el de Julio Quesada (cf. QUESADA, J. (2008). Heidegger de camino al holocausto. Madrid: Biblioteca Nueva), que ignora muchos textos publicados en el volumen 16 de las Obras completas.

24 Cf., respectivamente, DENKER, A. \& ZABOROWSKI, H. (eds.) (2009). Heidegger und der Nationalsozialismus. Heidegger-Jahrbuch 5 - Interpretationen. München: Karl Alber; GROSSER, F. (2011). Revolutionen Denken. Heidegger und das Politische. München: Beck Verlag; xoLocotzI, A. (2013). Heidegger y el nacionalsocialismo. Una crónica. México, D.F.: Plaza y Valdés 
A pesar del amplio consenso que existe en el ámbito de los estudios heideggerianos en torno a la filiación política de Heidegger, el debate continúa abierto, especialmente tras la publicación de nuevos documentos y discursos políticos depositados en el Archivo Heidegger y, por supuesto, la reciente edición de los Cuadernos negros. Estos cuadernos contienen información biográfica y política decisiva acerca de las turbulencias del periodo nazi. Entre otras cosas, queda claro que Heidegger rechaza la ideología nacionalsocialista de la dominación racial y biológica. Los Cuadernos Negros muestran que Heidegger intenta pensar filosóficamente algunas de las cuestiones planteadas por el nacionalsocialismo, en particular la cuestión de qué es lo que define al pueblo alemán (Volk). Apenas se dice nada sobre asuntos políticos concretos. Su interés se dirige hacia el significado espiritual y simbólico de la revolución nacionalsocialista más que a sus efectos concretos.

Los estudios de Farías, Sheehan, Ott y otros han demostrado con claridad las conexiones entre Heidegger y el nacionalsocialismo. Pero, con frecuencia, la discusión en torno a la postura política de Heidegger descansa en una concepción ahistórica del nazismo, que se tiende a concebir más como un mal moral que un complejo movimiento político, ideológico y social que desembocó en un holocausto sin parangón en la moderna historia europea. ${ }^{25}$ El nacionalsocialismo no es algo monolítico, sino un movimiento -especialmente en sus inicios- que aspira a una revolución política y social que se transformó de manera dramática en un régimen de devastación humana.

De ahí la necesidad de situar los textos heideggerianos en el contexto de la caída de la República de Weimar y la subida al poder del partido nacionalsocialista. En los últimos años el tema de la República de Weimar ha recobrado un interés inusitado, tal y como muestran algunas de las publicaciones más recientes. Entre ellas destacan la clásica aproximación cultural de Gay (1968), la radiografía de las consecuencias económicas tras el Pacto de Versalles de Fergusson (1975), el análisis sociológico de Weitz (2007), el estudio jurídico de la constitución de Weimar ofrecido por Jelinek (2010), la aproximación sociológica de Möller (2010) y la explicación histórica de Jay (1994). ${ }^{26}$ A ello cabe añadir

Editores; ZABOROWSKI, H. (2010). "Eine Frage von Irre und Schuld?" Martin Heidegger und der Nationalsozialismus. Frankfurt am Main: Fischer.

25 Cf. BAMBACH, Ch. (2003). Heidegger's Roots. Nietzsche, National Socialism, and the Greeks. Ithaca and London: Cornell University Press.

26 Cf., respectivamente, GAY, P. (1968). Weimar Culture. The Outsider as Insider. London and New York: Norton\&Company; FERGUSSON, A. (1975). When Money Dies: The Nightmare of the Weimar Collapse. London: William Kimber; WEITZ, D. (2007). Weimar Germany. Promise and Tragedy. Cambridge: Princeton University Press; JELINEK, W., BUHLER, O. y BORNATI, C. (2010). La constitución de Weimar. Madrid: Tecnos; MÖLleR, H. (2010). La República de Weimar. Una democracia inacabada. Madrid: Antonio Machado Libros; JAY, M. y KAES, A. (eds.) (1994). Weimar Republic Sourcebook. Berkeley, Los Ángeles and London: University of California Press. 
los estudios sobre la ideología nacionalsocialista de Benz (1993) y los análisis históricos del específico contexto académico de la universidad alemana de los años treinta compilados por Leaman (1993) y Martin (1991). ${ }^{27}$

En definitiva, por una parte, hay que analizar lo que Heidegger dijo -sus reflexionese hizo -sus hechos- durante el periodo del régimen nacionalsocialista; $y$, por otra, ver cómo esos hechos han de ser interpretados en relación con su filosofía y su contexto histórico. En otras palabras, tanto la "historia oficial" contada por el propio Heidegger como el "caso Heidegger" tienen que completarse -y, en parte, corregirse- sobre la base de investigaciones archivísticas, documentales, históricas y filosóficas. Aquí nos interesa centrar la atención en una lectura de las reflexiones heideggerianas en torno al judaísmo profundamente enraizada en el contexto social e histórico de la Alemania conservadora, una Alemania muy crítica con la República de Weimar.

\section{3. ¿Qué es Alemania? Arraigo, tierra natal y pueblo}

\subsection{La política de la tierra}

Heidegger tiene una particular visión de la historia del ser, en la que se establece una relación de privilegio entre los griegos y los alemanes -en concreto, entre los pensadores griegos y los poetas alemanes. Desde su perspectiva, la identidad alemana se forja lingüística, histórica y culturalmente en torno a la noción de "tierra natal" (Heimat o Heimatland). El espíritu alemán no se define a partir del modelo territorial del Estado nación, sino por el arraigo que los alemanes establecen con los lazos de su comunidad y su historia. Como se sabe, Heidegger rechazó con insistencia el biologismo de la ideología nazi y su retórica racista. Él parece estar más interesado en pensar filosóficamente algunos de los principales problemas del nacionasocialismo, en particular la cuestión de qué signifca ser un pueblo (Volk). ${ }^{28}$ Aquí pueblo no se piensa en términos racistas y biológicos.

27 Cf., respectivamente, BENZ, W., BUCHHEIM, H. y MOMMSEN, H. (eds.) (1993). Der Nationalsozialismus. Studien zur Ideologie und Herrschaft. Frankfurt am Main: Fischer; LEAMAN, G. (1993). Heidegger im Kontext. Gesamtüberblick zum NS-Engagement der Universitätsphilosophen. Berlin/Hamburg: Argument Verlag; MARTIN, B., JOHN, E., MüCK, M y OTT, H. (eds.) (1991). Die Freiburger Universität in der Zeit des Nationalsozialismus. Freiburg: Ploetz Verlag.

28 Obviamente lo político también juega un papel importante en el pensamiento de Heidegger durante los años del rectorado. En 1933/34, el estado nacionalsocialista encarna para él una continuación y realización del estado prusiano. A juicio de Heidegger, Bismarck cometió el errror de no incluir al proletariado en el estado. De ahí su interés y fascinación por el nacionalsocialismo: "nacional" expresa el elemento popular (völkisch); "socialismo" remite a la integración del trabajador. En ese contexto, Hitler es el Führer, la persona que representa y lleva a cabo la voluntad del pueblo (Volkswillen). En 1933/34, el Führer y el Führerprinzip tienen una presencia recurrente en la filosofia 
El pueblo se identifica con el espíritu de una nación . El Estado -como señala Heideggeres el modo de ser del pueblo. ${ }^{29}$

Heidegger está convencido de que la filosofía en sentido originario sólo puede llevarse a cabo en diálogo con la política. Pero se trata de una noción muy particular de política. En su caso no se trata tanto de política en un sentido institucional, legal y socioeconómico como de una política de la tierra, de una geopolítica, de una archi-política. ${ }^{30}$ Esta política de la tierra representa el espacio histórico y ontológico en el que el Dasein lucha por encontrar su lugar. Su propio sentido de ser está enraizado en la comunidad, en la tradición, en la historia. La tierra tiene aquí un significado ontológico. ${ }^{31}$ Ella se convierte en el espacio que permite desplegar las posibilidades humanas básicas, esto es, constituye la matriz, el ahí $(D a)$ en el que y contra el que el Dasein se auto-realiza como un determinado ente político. En la medida en que los seres humanos habitan sobre la tierra, éstos crean espacios cuyos bordes no coinciden necesariamente con los límites territoriales y/o geográficos. La tierra constituye lo que los griegos llaman chton: el lugar donde los humanos permanecen y crean una tierra natal (Heimatland). ${ }^{32}$

¿Cuál es el momento adecuado para llevar a cabo este tipo de política? Los turbulentos años de la República Weimar presentan la oportunidad esperada -no sólo para Heidegger

heideggeriana del Estado. Pero ya en 1934/35 se empiezan a detectar síntomas de distanciamiento y desilusión con el régimen nacionalsocialista y un creciente interés por la poesía de Hölderlin y la filosofía de Nietzsche. Para un anàlisis detallado de las estaciones del pensamiento heideggeriano durante el régimen nacionalsocialista véase el trabajo de GROSSER, F. (2011). Revolutionen denken. Heidegger und das Politische 1919 bis 1969. München: Verlag Beck, pp. 66-98.

$29 \mathrm{Cf}$. al respecto las interesantes observaciones de Zaborowski sobre el intento heideggeriano de formular una ontología de lo político, una meta-política a partir de una concepción espiritual del pueblo que nada tiene que ver con criterios biológicos y racistas (cf. ZABOROWSKI, H. (2010). "Eine Frage von Irre und Schuld?" Martin Heidegger und der Nationalsozialismus. Frankfurt am Main: Fischer, pp. 414-420. Sin duda, aquí se deja notar la influencia de la Filosofía del derecho de Hegel, a la que Heidegger dedicó varias sesiones de trabajo en el semestre de 1934/35 (cf. HEIDEGGER, M. (2011). Seminare Hegel-Schelling. Frankfurt am Main: Vittorio Klostermann, GA 86, pp. 59-185.

30 Cf. BAMBACH, Ch. (2003). Heidegger's Roots. Nietzsche, National Socialism, and the Greeks. Ithaca and London: Cornell University Press, p. 14.

31 Por ejemplo, el concepto de "tierra" empleado en El origen de la obra de arte no remite a una naturaleza idealizada y dada antes de la aparición de la cultura. La tierra, más bien, es una dimensión de la existencia del individuo que se manifiesta en la lucha con la cultura y el mundo. La tierra no es un fundamento estable, sino un espacio de realización de posibilidades de existencia creativas (cf. HEIDEGGER, M. (1997). “Der Ursprung des Kunstwerkes”. En Holzwege. Frankfurt am Main: Vittorio Klostermann, GA 5, p. 35s).

32 Esto se deja ver con claridad en las interpretaciones de algunos himnos de Hölderlin de las lecciones del semestre de invierno de 1934/35 (cf. HeIDEGGER, M. (1999). Hölderlins Hymnen "Germanien" und "Der Rhein". Frankfurt am Main: Vittorio Klostermann, GA 39, pp. 167ss). 
sino para gran parte del mundo académico alemán. ${ }^{33}$ La inestabilidad económica, la dislocación social y la agitación política del período de Weimar parecen presentar la ocasión propicia (kairós) para liberar a la filosofía del cosmopolitismo, el liberalismo y, por ende, la falta de arraigo (Bodenlosigkeit) característicos de la cultura urbana de Weimar. Para combatir esa falta de arraigo Heidegger intenta recuperar el acceso a las raíces profundas de Alemania y la tradición filosófica occidental. Eso explica la estrecha relación que se establece entre los poetas alemanes (Hölderlin, George, Trakl, Rilke) y los pensadores griegos (Heráclito, Parménides, Platón, Aristóteles). Ya en las lecciones del semestre de verano de 1924 Conceptos fundamentales de la filosofía aristotélica, Heidegger recuerda a sus estudiantes la necesidad de recuperar el suelo que mantiene vivo a la ciencia griega. ${ }^{34}$ A lo que alude Heidegger no es otra cosa que el mantenimiento en el suelo, la constancia (Ständigkeit) en la tierra (Boden). Este regreso a los orígenes alemanes de la tierra natal es una reivindicación común del ala conservadora del llamado "movimiento popular" (Volkstum). Autores como el conde Yorck de Wartenburg y Oswald Spengler son dos representantes de este movimiento que, entre otros, ejercieron una fuerte influencia sobre Heidegger.

\subsection{Yorck y el arraigo en la propia tierra natal}

Durante los mismos años en que Heidegger dedicaba un gran esfuerzo interpretativo a los textos de filosofía práctica y política de Aristóteles (1924/25), también están marcados por una lectura atenta de la correspondencia entre el conde Yorck de Wartenburg y Wilhelm Dilthey publicada en 1923. En las cartas de Yorck a Dilthey, que influyen de manera decisiva en el sentido de la historicidad de Ser y tiempo, Heidegger encuentra una importante fuente de inspiración para su concepto de "tierra natal" (Heimatland). En muchas de esas cartas, Yorck vuelve y una otra vez sobre el tema de la falta de arraigo (Bodenlosigkeit) de Alemania y defiende un tipo de vida enraizada en el suelo propio y en la tradición histórica. La permanencia en la propia tierra natal constituye un elemento primordial de la estabilidad (Ständigkeit) -tanto de la del individuo como la de la comunidad. Aquellos que abandonan su propio suelo en favor del flujo de capital y la vida urbana han perdido sus lazos con su propia identidad histórica. Yorck señala aquí a los judíos como ejemplo

33 Para un estudio detallado de las implicaciones de la Universidad de Friburgo con el nacionalsocialismo y, en particular, del rectorado de Heidegger véase MARTIN, B. (1991). "Universität im Umbruch: Das Rektorat Heidegger 1933/34". En E. JOHN, B. MARTIN, M. Mück y H. OTT (eds.), Die Freiburger Universität in der Zeit des Nationalsozialismus. Freiburg und Würzburg: Ploetz, pp. 9-23. 34 Cf. HEIDEGGER, M. (2002). Grundbegriffe der aristotelischen Philosophie. Frankfurt am Main: Vittorio Klostermann, GA 18, pp. 36-37. 
de este tipo de vida gobernada por el dinero y el afán de lucro: "Los judíos, toda esa tribu que carece de cualquier sentimiento hacia el suelo físico y psíquico." ${ }^{35}$

El interés que Yorck muestra por el lugar de nacimiento y por una vida asentada en la tierra natal genera una gran influencia en el pensamiento de Heidegger. Al reconfigurar la identidad alemana en términos de arraigo y autoctonía en lugar de criterios estrictamente económicos y territoriales, Yorck destaca una dimensión fundamental de la existencia alemana: su asentamiento en una tierra, cuyo verdadero sentido es histórico más que topográfico. La comprensión que Yorck tiene de la tierra natal y del paisaje local como fuerzas que dan forma al destino histórico alemán proveen a Heidegger con un modelo que le permite pensar la conexión entre arraigo (Bodenständigkeit) y destino (Geschick). En los parágrafos 73-77 de Ser y tiempo, Heidegger retoma el análisis de Yorck y despliega una particular lectura del destino de la existencia humana: el Dasein, en cuanto determinado por el cuidado (Sorge), nunca existe en solitario y desconectado de la herencia de su tradición. La lectura de Yorck le permite reconceptualizar el papel constitutivo de la tradición y del arraigo en la propìa tierra natal como dos elementos fundamentales que determinan la existencia individual y colectiva. Esa existencia -tanto la de los individuos como la de las comunidades- es algo dinámico y sometido a un constante proceso de revisión y reinterpretación.

Yorck resalta la necesidad de comprender al Dasein no como un sujeto aislado, monádico y burgués, sino como un ente cuyo ser está constituido por su generación. Eso significa que el destino de todo individuo (Schicksal) está estrechamente entretejido con el destino colectivo del pueblo (Volksgeschick) al que pertenece. El destino colectivo, el Ge-schick, no es algo dado de antemano. Se trata, más bien, de un búsqueda en común (Ge-) de las posibilidades históricas que la tradición envía (schicken) a una comunidad; posibilidades que en cada caso deben ser realizadas y apropiadas en confrontación con sus raíces históricas.

A juicio de Heidegger, el arraigo está ligado con la historicidad. El Dasein -entendido de manera colectiva como pueblo- sólo se convierte en lo que es (esto es, alemán) en la lucha y el esfuerzo por recuperar sus raíces en la historia, en el lenguaje y en la tierra natal. Sin embargo, durante los años veinte y el período de la República de Weimar, Heidegger nunca aborda explícitamente el significado de lo qué es ser alemán. Eso no se producirá hasta el estallido eufórico de la nacionalsocialismo en 1933, momento en el que Heidegger muestra un creciente interés por la cuestión del arraigo popular (völkische

35 YORCK (1970). "Katharsis". En GRÜNDER, L. (ed.). Die Philosophie des Grafen Paul Yorck von Wartenburg. Göttingen: Vandenhoeck\&Ruprecht, pp. 174-175. 
Bodenständigkeit) en diálogo abierto con la política de la revolución conservadora. ${ }^{36}$ La irrupción nacionalsocialista de 1933 proporcionó a Heidegger lo que Maquiavelo llamó l'occasione: la ocasión política, el momento kairológico, el instante oportuno para el pueblo alemán y el rol de liderazgo de su Führer. Más allá de los escritos, manifiestos y palabras de Heidegger, más allá de sus intenciones políticas, hay que comprender su postura política en el marco del conservadurismo académico de la época, uno de cuyos propósitos consiste en restablecer las raíces históricas del pueblo alemán. Ese espíritu de renovación se palpa muy bien en el famoso discurso del rectorado de mayo de $1933 \mathrm{La}$ auto-afirmación de la universidad alemana.

\subsection{La cuestión alemana}

Cuando afirmamos que Heidegger elabora conceptos como el de "tierra natal", "comunidad" y "pueblo" a partir de sus lecturas de Yorck y Spengler, no estamos sugeriendo que el uso de tal vocabulario explique por sí mismo su participación con el nazismo, aunque tampoco se puede negar que ello allana y facilita el camino para una interpretación positiva del movimiento nacionalsocialista. En nuestra opinión, el uso de tales términos en el contexto intelectual de la época no es meramente incidental. Ese trasfondo ideológico impensado se moviliza con facilidad en el momento de afirmar la alemanidad (Deutschtum), reivindicar los lazos de sangre, defender la pertenencia a un mismo suelo e invocar el sacrificio, el patriotismo y el nacionalismo.

En las postrimerías de los años veinte encontramos en Max Müller y Hans Jonas testimonios que confirman la inclinación heideggeriana hacia la nación alemana

36 Ferdinand Tönnies es uno de los principales representantes de este movimiento popular (völkisch). De acuerdo con él, Occidente está marcado por tipos de organización social: la sociedad (Gesellschaft) y la comunidad (Gemeinschaft). La primera es una asociación artificial que se basa en la idea de un contrato libre entre individuos motivado por el interés, mientras que la segunda se caracteriza por lazos familiares y de sangre, por compartir un lugar y una tierra comunes, por tener un mismo espíritu de pueblo. Las sociedades están gobernadas por el cálculo, la codicia, el poder, la ambición, la vanidad, el beneficio, la falta de espíritu y la explotación de la naturaleza y de los individuos. Las comunidades, en cambio, se mueven por la pasión, la sensualidad, el coraje, la piedad, la imaginación, el respeto de la naturaleza y la permanencia en la tierra natal. En palabras de Tönnies, "en el curso de la historia, la cultura del pueblo (Kultur des Volkstum) se ha transformado en una civilización del Estado (Zivilisation des Staatstum)." (TÖNNIES, F. (1963). Gemeinschaft und Gesellschaft. Darmstadt: Wissenschaftliche Buchgesellschaft, p. 251). En Spengler puede encontrarse un elaboración más profunda de las tesis de Tönnies en torno a la decadencia de la cultura y a los peligros del auge de la civilización. Heidegger entró en contacto con los motivos de la "comunidad", el "pueblo" y la "cultura" expresados por Tönnies a través de su lectura del libro de Spengler La decadencia de Occidente, lectura al que dedicó algunas clases durante los primeros cursos de Friburgo al inicio de los años veinte. 
(deutsche Volkstum) y sus simpatías hacia la ideología de la sangre y el suelo (Blut und Boden). Max Müller describe al Heidegger de Friburgo de 1928/29 de la siguiente manera: "Heidegger cultivaba con sus estudiantes un estilo completamente diferente al de otros profesores. Realizamos muchas excursiones. Por supuesto, la relación con el pueblo (Volk), la naturaleza y el movimiento estudiantil eran un tema recurrente de conversación. La palabra "nacional" (völkisch) le era muy cercana, si bien nunca la conectó con ningún partido político." ${ }^{37}$ Y Hans Jonas nos ofrece el siguiente relato: "Es cierto que en Heidegger siempre se podía detectar cierto punto de vista marcado por la idea de "la sangre y el suelo". Para él, su origen de la Selva Negra tenía una gran importancia. Eso se debe no sólo al hecho de que amaba el esquí y las montañas, sino que también tenía algo que ver con su posición ideológica: uno debía mantenerse cercano a la naturaleza. Algunas de sus observaciones mostraban una suerte de nacionalismo primitivo."38

Heidegger estaba realmente convencido de la necesidad de un cambio profundo y duradero de la realidad alemana cuando en la primavera de 1933 escribe una carta a Elisabeth Blochmann en la que se detecta un lenguaje revolucionario que marca el momento decisivo de su entrada en el reino de la política: "Para mí, la situación presente exige actuar al servicio de un gran cometido y participar en la construcción de un mundo fundado en el pueblo. Podemos descubrir esto, al igual que la vocación de los alemanes, en la historia de Occidente, pero sólo si nosotros mismos nos exponemos a y apropiamos de ella de una manera nueva. El tiempo para un primer despertar ha llegado." 39

El diagnóstico heideggeriano de la sociedad alemana contemporánea concluye con una invitación al cambio, un cambio que debe desembocar en una reforma de la universidad. Ese es uno de los mensajes expresados en el Discurso del Rectorado. Por cierto, encontramos proclamaciones similares en rectores de otras universidades alemanas de la misma época. Por ejemplo, las de Hans Heyse en la Universidad de Königsberg y las de Ernst Krieck en la Universidad de Frankfurt. Heyse, Krieck y Bäumler, entre otros muchos, estaban convencidos de que el camino de la transformación de la sociedad alemana pasaba por una reforma universitaria y un retorno a la cultura griega. Una reforma sazonada con una intensa retórica patriótica, marcial, nacional y heroica; una reforma que invoca la dureza y la severidad. En este contexto, Heidegger se ve a sí mismo como un filósofo de transición

37 MÜLLER, M. (1986) „Martin Heidegger. Ein Philosoph und die Politik“. Freiburger Universitätsblätter, p. 18.

38 JonAs, H. (1990). "Heidegger's Resoluteness". En G. NESKE and E. KETtering (eds.). Martin Heidegger and National Socialism. London: Continuum, p. 200.

39 heidegger, M. y Blochmann, E. (1990). Briefwechsel 1918-1969. Marbach: Deutsche Schillergesellschaft, p. 60. 
en un tiempo de transición que se enfrenta heroicamente a los peligros que acechan a la universidad $y$, por ende, a Alemania en una era dominada por el nihilismo.

Aquí también se dejan sentir con fuerza las huellas de Ernst Jünger y Friedrich Nietzsche. Ambos ayudaron a Heidegger a comprender las profundas implicaciones metafísicas de su tiempo. A partir de sus lecturas de Nietzsche y de Jünger, iniciadas a principios de los años treinta, Heidegger empieza a tomar conciencia de que la maquinación y el nihilismo son las fuerzas que animan el destino de Occidente. Las causas políticas y metafísicas del nihilismo son la voluntad de poder y la falta de arraigo del mundo moderno. Heidegger quiere sacudir las conciencias adormecidas de sus contemporáneos a través de un mensaje de revelación (Offenbarung); una revelación que consiste en un salto (Sprung) hacia el origen (Ursprung).

En el centro del creciente interés que Heidegger empieza a mostrar por Jünger, Nietzsche, George y Hölderlin se encuentra la pregunta fundamental: “¿Qué es Alemania?” Alemania puede determinar su destino de tres maneras:

A) Al estilo de Jünger, que habla de una "Alemania de los trabajadores" en el marco de un nuevo nacionalismo de tintes sociales y militares;

B) Al estilo del nacionalsocialismo, que concibe una "Alemania sometida al Führerprinzip y la teoría racial";

C) Al estilo de Stefan George, que poetiza la idea de Hölderlin de una "Alemania entendida como patria y tierra natal".

La patria alemana (deutsche Vaterland) es el origen silente y oculto que todavía está a la espera de ser descubierto en el momento adecuado. De nuevo nos encontramos con la elaboración del mito de la tierra natal (Heimatland) que responde a una clara estructura kairológica del tiempo.

De hecho, los Cuadernos negros arrancan con una observación sobre la esencia de los alemanes: "Ser alemán: la carga más íntima de la historia de Occidente a la que se está arrojada y que hay que cargar sobre las espaldas". ${ }^{40}$ Una de las preguntas centrales que vertebra muchas de las reflexiones heideggerinas contenidas en los Cuadernos negros es la de "¿Quiénes somos nosotros?". Aquí se produce un paso de la Jeweiligkeit, del conocido ser-en-cada-caso-mío del Dasein analizado en Ser y tiempo, a la Jeunsrigkeit del segundo Heidegger, al ser-en-cada-caso-nuestro, es decir, se da un paso del destino individual al destino colectivo de la nación alemana. Más allá de los legítimos juicios morales y políticos que se puedan formular contra la implicación heideggeriana con el

40 HEIDEGGER, M. (2014). Überlegungen VII-XI. Frankfurt am Main: Vittorio Klostermann,GA 95, p. 1. 
nacionalsocialismo, ése nos parece el marco desde el que cabe interpretar filosóficamente los pasajes de Heidegger sobre el judaísmo que, como se sabe, se integran en su crítica de la modernidad y en sus reiterados ataques al americanismo y bolchevismo.

Retomando la relación que Hölderlin establece entre los alemanes y los griegos, Heidegger encuentra una fuente de inspiración para su ideal de una tierra natal alemana. Los alemanes -como escribe a Schwoerer para recomendar a uno de sus estudiantesdeben reafirmar su legado o sufrir el destino de una "creciente judaización" (Verjudung). ${ }^{41}$ La carta a Schwoerer concluye situando la diferencia entre alemanes y judíos en el lenguaje de la tierra natal. Los alemanes están profundamente arraigados a su tierra natal (Heimatland), a su suelo patrio (Vaterland), mientras que los judíos son un pueblo marcado por la diáspora, la migración, el éxodo, esto es, por la falta de arraigo (Bodenlosigkeit). La forma de vida urbana y desarraigada de los judíos puede llegar a representar un peligro para la comunidad del pueblo (Volksgemeinschaft). Desde la perspectiva de Heidegger, según el cual la autoctonía se basa en el arrigo en la tierra natal, los judíos son un pueblo desarraigado. Como comenta Derrida, la única forma de arraigo que conocen los judíos es la de la palabra y la escritura. ${ }^{42}$ De ahí que no nos deba sorprender que en 1933 Heidegger adviertiera a Jaspers de la "peligrosa red internacional de los judíos"43 o que en Contribuciones a la filosofía declare que "el bolchevismo es judío". ${ }^{44}$ Sin embargo, hay que ser cautelosos a la hora de descifrar el sentido de las afirmaciones heideggerianas. Heidegger no es un típico antisemita racista. En repetidas ocasiones rechaza el racismo biológico. ${ }^{45}$

\section{4. ¿Antisemitismo o antijudaismo?}

Cada vez que se habla de la relación entre Heidegger y el nacionalsocialismo se suele plantear la pregunta de si Heidegger fue antisemita o si dejan detectar tendencias antisemitas en su obra filosófica. La respuesta a este tipo de preguntas no es nada fácil

41 Cf. SIEG, U. (1989). "Die Verjudung des deutschen Geistes. Ein unbekannter Brief Heideggers". Die Zeit, núm 52 (22 de diciembre de 1989).

42 Cf. DeRridA, J. (2002). "Edmond Jabés and the Question of the Book" (1981). En Writing and Difference. London and New York: Routledge.

43 JASPERS, K. (1977). Philosophische Autobiographie. München: Piper, p. 101.

44 HeIDEgGeR, M. (1979). Beiträge zur Philosophie. Vom Ereignis. Frankfurt am Main: Vittorio Klostermann, GA 65, p. 54. Pero eso no significa aniquilar a los judíos. Heidegger rechaza la idea de un dominio de la raza y el control político (Heidegger, GA 65, p. 397.)

45 Cf. POLt, R. (2009). "Jenseits von Kampf und Macht. Heideggers heimlicher Widerstand". En A.DENKER y H. ZABOROWSKI (eds.). Heidegger Jahrbuch 5-Interpretationen. Freiburg/München: Karl Alber, pp. 156, 159, 169 y 171. 
por las implicaciones políticas y las ramificaciones morales que trae consigo. Desde luego, no se puede responder con un simple "sí" o "no". Antes de responder a la pregunta de si Heidegger y su obra son antisemitas hay que tener claro que sé entiende por antisemitismo y, por ende, qué se entiende por antijudaísmo. ${ }^{46}$ Hay que tener claras las diferencias entre ambos fenómenos para no caer presos de juicios rápidos.

Así, por ejemplo, se habla de un antijudaísmo de orden religioso y cultural y de un antisemitismo de orden biológico y racista. Por una parte, hay que distinguir entre una tradición de hostilidad contra los judíos como miembros de una comunidad religiosa que se remonta al siglo I y, por otra, un movimiento político-social de rechazo y discriminación de la "raza judía". Evidentemente, no se trata de minimizar la culpa de Heidegger. En la discusión con el antisemitismo nacionalsocialista resulta difícil encontrar las palabras adecuadas para describir los sucesos acontecidos, en particular cuando se intenta explicar el holocausto. Tampoco es fácil distinguir con claridad las fronteras entre "antisemitismo" y "antijudaísmo". El uno no se puede entender sin el otro. Las fronteras entre ambos fenómenos son fluctuantes.

¿Se puede acaso distinguir con tanta claridad entre dos tipos de enemistad contra los judíos? ¿No significaría eso una exculpación del antijudaísmo en comparación con el antisemitismo y su búsqueda de una "solución final" a la cuestión judía? Con todas las dificultades implicadas en la diferenciación entre anti-judaísmo y anti-semitismo y siendo conscientes de la precaución que hay que mostrar en el uso de esa diferenciación, no se puede perder de vista que existieron y existen diferencias de peso entre: a) un prejuicio ideológico condicionado por motivos culturales y religiosos contra los judíos y b) el propósito justificado de manera pseudocientífica de exterminar a toda la "raza judía". Como comenta Zaborowski, incluso si prescindimos distinguir entre antijudaísmo y antisemitismo y optamos por el uso del concepto general "antisemitismo", nos veríamos obligados a distinguir entre diferentes tipos de antisemitismo -al menos con respecto a la posición social de los judíos y al uso de la violencia contra ellos. ${ }^{47}$ Cuando se discute la relación de Heidegger con los judíos hay que tener en cuenta una serie de diferenciaciones

46 Para una historia del antisemitismo resulta obligada la referencia al trabajo de BENZ, W. (2004). Was ist Antisemitismus? München: Beck, pp. 9-26. También resultan interesantes los estudios de BENZ, W. y BERGMANN, W. (eds.) (1997). Vorurteil und Völkermord. Entwicklungslinien des Antisemitismus. Freiburg: Herder; SCHOEPS, J. y SCHLÖR, J. (eds.) (1995). Antisemitismus. Vorurteile und Mythen. München/Zürich: Piper; CLAUSSEN, D. (1987). Vom Judenhass zum Antisemitismus. Materialen einer verleugneten Geschichte. Darmstadt. Finalmente, remitimos a la instructiva historia conceptual de la entrada "antisemitismo" en SCHMITZ-BERNING, C. (2000). Vokabular des Nationalsozialismus. Berlin: De Gruyter, pp. 34-39.

47 Cf. ZABorowsKI, H. (2010). "Eine Frage von Irre und Schuld?" Martin Heidegger und der Nationalsozialismus. Frankfurt am Main: Fischer, pp. 603-604. 
y matizaciones en torno a lo que se quiere decir con el término "antisemitismo". No nos podemos limitar a unas cuantas fuentes. ${ }^{48}$ El camino del pensar y la vida de Heidegger también tienen que considerarse desde su particular contexto histórico.

A nuestro juicio, hay que establecer una clara diferencia entre antisemitismo entendido como animosidad racial y biológica contra los judíos y antijudaísmo como reflejo de una larga tradición europea contra el pueblo y la religión judíos. A tenor de la evidencia documental disponible resulta difícil hablar de un antisemitismo sistemático en la filosofía de Heidegger. ${ }^{49}$ Lo que sí podemos detectar en Heidegger son huellas profundas de un antijudaísmo espiritual y cultural, particularmente presente en las esferas universitarias y académicas. No cabe duda de que la relación de Heidegger con el judaísmo es altamente problemática y ambivalente, pero no podemos describir su posición como unilaterlamente antisemita, si por antisemitismo entendemos la persecución racial y aniquiliación sistemática de los judíos.

¿Cómo debe responderse entonces a la pregunta de si Heidegger fue antisemita o no? Ya a finales de los años veinte circulaba el rumor de que Heidegger era antisemita. Toni Cassirer, la mujer de Ernst Cassirer, reconoce en su autobiografía que "la inclinación [de Heidegger] hacia al antisemitismo no nos era extraña"..$^{50} \mathrm{Y}$ a principios de los años treinta -como señala Bultmann- se extendió el rumor de que Heidegger había ingresado en el Partido Nacionalsocialista. ${ }^{51}$ Incluso su antiguo amigo y colega, Karl Jaspers, mostraba en su informe redactado en 1945 para la Universidad de Friburgo sus retecencias respecto a la

48 En su obra, en particular en los múltiples volúmenes que integran la Gesamtausgabe, no se detecta un antisemitismo sistemático que nos permita hablar de un antisemitismo filosófico o, como afirma Faye, de una introducción del nazismo en la filosofía. Otra cosa es valorar las afirmaciones heideggerianas sobre el judaísmo desde la óptica de su proyecto filosófico. Esa labor, por supuesto, puede realizarse al mismo tiempo que uno se sigue interrogando por la actitud personal y política de Heidegger y sus simpatías por ciertos aspectos de la ideología nacionalsocialista. Véase en este contexto el trabajo de Roubach sobre la recepción heideggeriana en Israel (cf. ROUBACH, M. (2009). "Die Rezeption Heideggers in Israel". En A. DENKER y H. ZABOROWSKI (eds.). Heidegger-Jahrbuch 5. Heidegger und der Nationalsozialismus. Freiburg/München: Karl Alber, pp. 419-432).

49 En este sentido nos sentimos más próximos a las posturas más moderadas de Grosser, Martin, Safranski, Sluga, Thöma, Xolocotiz y Zaborowski que a las acusaciones de Faye y Farías. A este respecto se puede mencionar la carta que Herbert Marcuse escribe a Heidegger en agosto de 1947, en la que éste le acusa de una total falta de sensibilidad más que de un antisemitismo malvado y perverso (cf. MARCUSE, H. (1989). "Brief an Martin Heidegger vom 28. August 1947". En B. MARTIN (ed.). Martin Heidegger und das „Dritte Reich". Ein Kompendium. Darmstadt: Wissenschaftliche Buchgesellschaft, p. 156).

50 CASSIRER, T. (2003). Mein Leben mit Ernst Cassirer. Darmstadt: Wissenschaftliche Buchgesellschaft, p. 187.

51 Cf. HEIDEgGER, M. y BULtMANN, R. (2009). Briefwechsel 1925 bis 1975. Frankfurt am Main: Vittorio Klostermann, pp. 187s y 191s. El propio Heidegger confirma la existencia de tales rumores en una 
actitud que Heidegger mostraba hacia los judíos. ${ }^{52}$ Y en las cartas a su mujer, Elfride Preti, publicadas en 2005, Heidegger ya hablaba en 1916 de la "judaízación de nuestra cultura y de las universidades". ${ }^{53}$ Heidegger vuelve a hablar de la "judaízación" (Verjudung) en unos términos similares en una carta dirigida en 1929 a Victor Schwoedrer, Vice-presidente de la Notgemeinschaft der Deutschen Wissenschaft. ${ }^{54}$ En el caso de las cartas a su esposa y a Schwoedrer se trata de dos casos que parecen mostrar con claridad cierto antisemitismo racista.

De nuevo, se suscita la misma cuestión planteada al inicio: ¿qué tipo de antisemitismo sostiene Heidegger? A la luz de la documentación disponible, parece difícil hablar de un antisemitismo racista o biológico en Heidegger. También en los Cuadernos negros y otros escritos encontramos pasajes en los que Heidegger se muestra extremadamente crítico con este tipo de antisemitismo. Es cierto que Heidegger establece una diferencia entre judíos y no-judíos, pero esa diferencia no se sustenta en criterios biológicos. Sus comentarios sobre los judíos se realizan desde la perspectiva del espíritu y no de la raza. Así, por ejemplo, en su libro sobre Nietzsche deja claro que "la biología como tal nunca decide sobre lo qué es la vida". ${ }^{55}$ La verdadera cuestión relativa a la relación heideggeriana con los judíos no se puede dirimir de esta manera. Más bien hay que tomar en consideración como su aproximación filosófica a la tradición hebraica constituye un momento decisivo en la forma que interpreta la entera historia de la filosofía. Heidegger no está interesado -al menos filosóficamente hablando- en legitimar el exterminio de los judíos, sino en alcanzar una comprensión crítica de su presente. Su diagnóstico del presente se ve fuertemente influenciado por su interpretación del nihilismo nietzscheano: el presente es un tiempo dominado por el principio metafísico de la voluntad de poder. La introducción de una "selección y cría racial" (Rassenzüchtung) de la que habla Heidegger

carta a Hannah Arendt del invierno de 1932/33 (cf. HEIDEGGER, M. y ARENDT, H. (1999). Briefwechsel 1925 bis 1975. Frankfurt am Main: Vittorio Klostermann, p. 68).

52 Cf. HEIDEgGgeR, M. y JASPERS, K. (1990). Briefwechsel 1920-1963. Frankfurt am Main: Vittorio Klostermann, p. 270.

53 Heidegger, M. y PETRI, E. (2005). "Mein liebes Seelchen!" Briefe Martin Heideggers an seine Frau Elfride, 1915-1970. München: Deutsche Verlags-Anstalt, p. 51. Sin embargo, doce años más tarde escribe a su mujer que "sin duda, los 'judíos' son 'los mejores'." (HEIDEGGER y PETRI, ibid., p. 156). Resulta difícil sostener la tesis de que Heidegger era una antisemita espiritual en los años veinte. Esa situación cambia al principio de los años treinta con la creciente importancia concedida a las cuestiones del pueblo y la nación alemanas.

54 Cf. SIEG, U. (1989). "Die Verjudung des deutschen Geistes. Ein unbekannter Brief Heideggers". Die Zeit, num. 52 (22 de diciembre de 1989).

55 HeIdegGer, M. (1989). Nietzsche I. Pfullingen: Neske, p. 520. 
en sus lecciones de los años treinta sobre Nietzsche, ${ }^{56}$ no tiene nada que ver-como afirma Faye-con "una selección de la raza como la que en esos tiempos se pone sangrientamente en marcha con el nacionalsocialismo." ${ }^{57}$ No se trata de una legitimación ontológica del racismo nacionalsocialista. La "cría del ser humano" (Züchtung des Menschen) es la culminación de la metafísica de la subjetividad, es la expresión máxima de la técnica moderna en su intento de explotar los recursos naturales y humanos, es un producto de la maquinalización (Machinalisierung) que gobierna el presente. Heidegger opina que Nietzsche es el primer en reconocer el carácter metafísico de la máquina, que convierte al ser humano en un tipo (Typ), en una simple figura (Gestalt) a la que se le puede imprimir una forma, en un material de experimentación (Versuchsmaterial). ${ }^{58}$

A este respecto, se suele citar el pasaje de las Conferencias de Bremen para sostener la tesis de que el pensamiento heideggeriano es en el fondo antisemita. Este el caso de de Wolin y Faye, entre otros. En la conferencia de 1949 intitulada El engranaje (Das Gestell) se dice: "La agricultura es ahora una industria alimentaria mecanizada, en esencia lo mismo que la fabricación de cadáveres en las cámaras de gas y los campos de exterminio, lo mismo que bloquear y matar de hambre a países, lo mismo que la fabricación de bombas hidrógenas." 59 ¿Cómo se puede colocar la "fabricación de cádaveres" junto a la "industria alimentaria mecanizada"? Más allá de la insensibilidad heideggeriana y de la discusión moral sobre el holocausto, Heidegger quería pensar filosóficamente los motivos profundos de la "fabricación de cadáveres en las cámaras de gas". Desde la perspectiva de la crítica heideggeriana de la técnica que se extiende de manera planetaria, la ·fabricación de cadáveres es la expresión y la consecuencia de la desertización espiritual inherente a la voluntad de poder. Esta voluntad reduce cualquier cosa, incluso cualquier persona o colectivo, a simple objeto de uso y de explotación allende de cualesquieras consideraciones humanas, sociales, políticas, religiosas o morales. Uno puede estremecerse ante la insensibilidad y la "supuesta" ignorancia de Heidegger, pero con ello no se hace justicia a su pensamiento. Por una parte, las interpretaciones de Faye y Farías y, en menor parte,

56 Cf. HeIDEgGER, M. (1997). Nietzsche. Frankfurt am Main: Vittorio Klostermann, GA 6.2, p. 309. 57 fAYE, E. (2008). "Heidegger, der Nationalsozialismus und die Zerstörung der Philosophie". En B. Taureck (ed). Politische Unschuld? In Sachen Martin Heideggers. München: Wilhelm Fink, p. 53.

58 HEIDEGGER, M. (2007). Nietzsches Metaphysik. Frankfurt am Main: Vittorio Klostermann, GA 50, pp. 55 s.

59 HEIDEGGER, M. (2005). Bremer und Freiburger Vorträge. Frankfurt am Main: Vittorio Klostermann, GA 79, p. 27. Para una interpretación crítica de este pasaje, véase THöMA. D. (1990). Die Zeit des Selbst und die Zeit danach. Zur Kritik der Textgeschichte Martin Heideggers. Frankfurt am Main: Suhrkamp, pp. 626ss. 
las de Taureck, extraen pasajes fuera de su contexto y, por otra, no perecen establecer la necesaria diferenciación entre antijudaísmo y antisemitismo.

En el caso de Heidegger, nos encontramos ante un tipo de antisemitismo que podemos calificar de "religioso", "cultural" o "espiritual". En una carta dirigida a Arendt, en la que comenta la existencia de rumores sobre su antisemitismo, leeemos que: "Por lo demás, en cuestiones relacionadas con la universidad soy igual de antisemita que hace diez años en Marburgo. Este antisemitismo incluso encontró el apoyo de Jacobstahl y Friedländer. Esto no tiene nada que ver con relaciones personales (por ejemplo, Husserl, Misch, Cassirer y otros."60 Cuando Heidegger habla de la "judaízación" (Verjudung) los hace desde un determinado contexto cultural. Nuevamente hay que andarse con cuidado y evitar exculpar a Heidegger como un producto del espíritu de su época. Pero, por otra parte, tampoco 'puede caerse en acusaciones generalizadas. Parece que para cada prueba de antisemitismo encontramos otra prueba en contra. ${ }^{61}$ También se da el caso de que los documentos existentes pueden interpretarse de diversa manera. Sin duda, este antisemitismo cultural o espiritual se vio reforzado por el antisemitismo pseudo-científico del nacionalsocialismo. Una vez más: no se trata de quitar importancia al anti-semitismo de Heidegger. Pero tampoco cabe deducir una relación directa con la Shoah como la que muestra la radicalizada ideología racista del nazismo.

La cuestión de la culpa y de la relación heideggeriana con el judaísmo es ciertamente problemática y, a tenor de las últimas afirmaciones contenidas en los Cuadernos negros, muy espinosa. Una relación que nada tiene que ver con cuestiones políticas, sino que más bien parecen enmarcarse en su interpretación del destino metafísico de un Occidente dominado por la ciencia y la técnica. ${ }^{62}$ El distanciamiento heideggeriano del espíritu

60 HEIDEGGER, M. y ARENDT, H. (1999). Briefwechsel 1925 bis 1975. Frankfurt am Main: Vittorio Klostermann, p. 69.

61 Por ejemplo, encontramos testimonios de la ambivalente relación heideggeriana con los judíos en una carta a su mujer del año 1932. En ella expresa su desencanto con las capacidades filosóficas de Baeumler, aunque ensalza su valor como historiador (cf. HEIDEGGER, M. y PETRI, E. (2005). "Mein liebes Seelchen!" Briefe Martin Heideggers an seine Frau Elfride, 1915-1970. München: Deutsche Verlags-Anstalt, p. 176). De esta ambivalencia también de cuenta una carta de Jaspers de 1945 dirigida a la Comisión de Depuración: "En los años veinte Heidegger no era un antisemita. Sus palabras sobre el judío Fraenckel demuestran que, al menos en 1933, mostraba ciertas conexiones antisemitas. Eso no excluye, como asumo, que en otros casos el antisemitismo era contrario a su conciencia y a su gusto." (HEIDEGGGER, M. y JASPERS, K. (1990). Briefwechsel 1920-1963. Frankfurt am Main: Vittorio Klostermann, p. 271)

62 Como sostiene Donatella di Cesare, la crítica de Heidegger adopta en muchos momentos un tono mesiánico (cf. entrevista publicada el 18 de diciembre en la La Reppublica, p. 40). Ese tono mesiánico, espiritual y religioso se palpa con claridad en la idea del último dios que encontramos en Contribuciones a la filosofía. En ellas se afirma que sólo los venideros son la verdadera voz 
urbano de los judíos no es el resultado de un racismo biológico, sino la consecuencia de su análisis de la metafísica de la subjetividad y el nihilismo. Desde esa perspectiva, los judíos representan la racionalidad vacía y el espíritu de cálculo característico de la era moderna. Como señala en los Cuadernos negros: "La pregunta por el papel de judaísmo no es racista, sino una pregunta metafísica acerca del tipo de la humanidad.." ${ }^{3}$ Puede que uno no comparta la crítica heideggeriana de la técnica moderna, incluso uno puede preguntarse si la comprensión heideggeriana de la modernidad no es demasiado unilateral y simplificada. Pero si uno analiza la confrontación de Heidegger con la modernidad a partir de los textos disponibles resulta altamente problemático afirmar que Heidegger justifique y legitime el exterminio de los judíos. ¿Antijudaísmo en Heidegger? Sin duda. ¿Antisemitismo? Sí, siempre y cuando no se asocie de manera directa con la interpretación racista del pueblo y la política de exterminio ejercida por el nacionalsocialismo. ¿Debemos ser indulgentes con un gran pensador como Heidegger? Probablemente, no. Pero tampoco podemos ignorar su legado filosófico. En cualquier caso, los Cuadernos negros nos invitan a reflexionar sobre la responsabilidad de la filosofía hacia la política.

del pueblo y que el renacimiento del pueblo acontecerá muy probablamente por medio de un despertar religioso. El pueblo tiene que encontrar a su dios, y los venideros deben iniciar esa búsqueda (cf. HEIDEgGER, M. (1979). Beiträge zur Philosophie. Vom Ereignis. Frankfurt am Main: Vittorio Klostermann, GA 65, 319 y 398).

63 HEIDEGGER, M., Überlegungen XIV (GA ....). Frankfurt am Main: Frankfurt am Main, p. Cf. cita y comentario de Trawny 